\title{
OSSEOINTEGRATION OF TITANIUM IMPLANTS WITH A NOVEL SILVER COATING UNDER DYNAMIC LOADING
}

\author{
S. Stein, L. Kruck, D. Warnecke, A. Seitz, L. Dürselen and A. Ignatius* \\ Institute of Orthopaedic Research and Biomechanics, Centre for Trauma Research Ulm, \\ Ulm University Medical Centre, Ulm, Germany
}

\begin{abstract}
Postoperative implant-associated infections are a severe complication in orthopaedics and trauma surgery. To address this problem, a novel implant coating was recently developed, which allows for the release of low concentrations of bactericidal silver. For an intended use on load-bearing endoprostheses, stable bone integration is required. The aim of the present study was to evaluate the biocompatibility and osseointegration of titanium implants with the novel coating in a mechanically loaded bone-defect model in sheep.

Silver-coated devices were implanted into weight-bearing and non-weight-bearing tibial and femoral bone defects whereas, in the control group, uncoated titanium implants were inserted. The bony integration of the implants was assessed mechanically and histologically after 6 months. Silver concentrations were assessed in peripheral blood, liver, kidney and local draining lymph nodes as well as at the implantation site.

After 6 months, shear strength at the interface and bone apposition to the implant surface were not significantly different between coated and uncoated devices. Mechanical loading reduced bony integration independently of the coating. Silver content at the implantation site was larger in the group with silver-coated implants, yet it remained below toxic levels and no cytotoxic side effects were observed.

Concluding, the novel antibacterial silver coating did not negatively influence bone regeneration or implant integration under mechanically unloaded and even loaded conditions, suggesting that the silver coating might be suitable for orthopaedic load-bearing implants, including endoprostheses.
\end{abstract}

Keywords: Silver, antibacterial coatings, orthopaedic implants, load-bearing implants, periprosthetic infections, postoperative infections.

*Address for correspondence: Prof. Dr Anita Ignatius, Institute of Orthopaedic Research and Biomechanics, Centre for Trauma Research Ulm, Ulm University Medical Centre, Helmholtzstraße 14, 89081 Ulm, Germany. Telephone number: +4973150055301 Fax number:+4973150055302 Email: anita.ignatius@uni-ulm.de

Copyright policy: This article is distributed in accordance with Creative Commons Attribution Licence (http://creativecommons.org/licenses/by-sa/4.0/).

\section{Introduction}

Postoperative infections are a severe complication in orthopaedics and trauma surgery and are associated with significant patient morbidity. The presence of an orthopaedic implant at the surgical site increases the susceptibility to infections because of a compromised immune response at the bone-implant interface and potential biofilm formation on the device surface (Busscher et al., 2012; Rochford et al., 2012; ter Boo et al., 2015). For internal fixation devices, an overall infection rate of $5 \%$ is reported (Darouiche, 2004). However, the incidence can dramatically increase, for example, in the case of open fractures (McGraw and Lim, 1988; Trampuz and Widmer, 2006). Accordingly, a more recent randomised clinical trial of tibial shaft fractures has revealed an infection risk of $2 \%$ for closed tibial shaft fractures as compared to $8.8 \%$ for open fractures (Bhandari et al., 2008). Following primary hip and knee replacement, infection rates are $<1 \%$, but can increase up to $40 \%$ after revision surgery (Kurtz et al., 2008; Trampuz and Widmer, 2006; Widmer, 2001). The clinical and socioeconomic consequences of implant-associated infections are tremendous. Median treatment costs for orthopaedic trauma patients with surgical site infections are almost twice as high as treatment costs for noninfected patients (Thakore et al., 2015). A growing proportion of surgical site infections are caused by multi-resistant pathogens, leading to a substantially increased patient morbidity and mortality as well as a further increase in treatment costs (Anderson et al., 
2007; Parvizi et al., 2010). This emphasises the need for effective measures to prevent surgical-site infections in orthopaedic and trauma surgery.

Antibacterial coatings can prevent bacterial biofilm formation on a device surface and could contribute to a reduction in implant-associated infections (ter Boo et al., 2015). However, due to the emerging microorganism drug-resistance, the widespread clinical use of conventional antibiotics, which are usually applied on orthopaedic implants for treatment and prevention of surgical-site infections, has to be doubted and reconsidered. Silver appears to be particularly interesting for this application, because it effectively acts against a broad spectrum of bacteria, including multiresistant bacterial strains, viruses and fungi (Alt et al., 2004; Atiyeh et al., 2007; Brutel de la Riviere et al., 2000; Elechiguerra et al., 2005). Therefore, silver is clinically well established as an antimicrobial agent and is used for various applications, such as implant coatings (Atiyeh et al., 2007; Hardes et al., 2010; Hollinger, 1996). Metallic silver gets ionised in the wound fluid and the highly reactive silver ions bind to bacterial cell membranes, leading to cell death through induced structural changes and deterioration of membrane function. Furthermore, silver ions interfere with DNA replication and inhibit oxidative enzymes and the respiratory chain, thus impairing important cell functions (Brutel de la Riviere et al., 2000; Hollinger, 1996; Percival et al., 2005). Because of this multifactorial mechanism of action, bacteria rarely develop resistance to silver (Ahrens et al., 2006). Health risks associated with systemic silver ion absorption are generally considered to be low; however, high silver doses may be toxic to human cells and can lead to adverse side effects, for example, local argyrosis or systemic argyria (Lansdown, 2010). Therefore, the concentration of silver ions released from an implant surface has to be reduced to a therapeutically effective minimum (Chambers et al., 1962; Tweden et al., 1997).

To address this issue, a novel antibacterial coating for orthopaedic implants was recently developed, which consists of $\mathrm{SiO}_{\mathrm{x}} \mathrm{C}_{\mathrm{y}}$ plasma polymer layer with embedded elemental silver particles (Khalilpour et al., 2010). The coating can be applied to a variety of substrates (titanium, stainless steel, cobalt-chromium, polyether ether ketone, etc.) with a thickness of $<100 \mathrm{~nm}$, thereby enabling antibacterial treatment of even microstructured surfaces. Through controlled release of low-dose silver ions, bacterial adhesion and biofilm formation on an implant surface should be prevented. In addition to its low silver content, the main advantage when compared to already available silver-coated orthopaedic devices is that the silver is embedded and, thus, not in direct contact with the surrounding soft tissue. Previous studies have demonstrated the antimicrobial efficacy of the novel coating in vitro and in an in vivo infection model as well as its biocompatibility in vivo using a subcutaneous implantation model in rabbits (Fabritius et al., 2020; Khalilpour et al., 2010). Moreover, the coating has demonstrated efficacy in clinical use on veterinary fracture-fixation devices (BioMedtrix, Whippany, NJ, USA). However, there are no scientific data available to show whether the new silver coating influences bone regeneration and implant integration when implants are inserted directly into bone. Unlike fracture-fixation devices, which are used for the temporary reposition and stabilisation of fractured bones, solid integration into the surrounding bone is of utmost importance for the biomechanical stability and functionality of load-bearing devices, e.g. endoprostheses. Therefore, the aim of the present study was to evaluate the osseointegration of titanium implants with the new silver coating in a mechanically loaded implantation model in sheep (Ignatius et al., 1997; Simon et al., 2003).

\section{Materials and Methods}

The study was approved by the local regulatory authority (no. 1380, Regierungspräsidium Tübingen, Germany). All animal procedures were performed according to the national and international regulations for the care and use of laboratory animals. The study follows the standard ISO 10993-6: 2016 guidelines (Web Ref. 1), with a small variation: coated and control implants were not implanted into the same animals, but in two different groups. This was necessary as elemental analyses of local and systemic silver contents were additionally performed to assess any potential silver accumulation.

\section{Implants with antibacterial coating}

Titanium-vanadium implants $\left(\mathrm{Ti}_{6} \mathrm{Al}_{4} \mathrm{~V}\right)$ were coated with a polysiloxane layer with embedded elementary silver particles (HyProtect ${ }^{\mathrm{TM}}$, Bio-Gate AG, Nuremberg, Germany) as previously described (Khalilpour et al., 2010). The coating was applied to the titanium implant in a three-step process. First, a $\mathrm{SiO}_{x} \mathrm{C}_{\mathrm{y}}$ base layer was applied to the implant surface by chemical vapour deposition. Subsequently, silver clusters $\left(\sim 2.7 \mu \mathrm{g} / \mathrm{cm}^{2}\right)$ were deposited on the base layer by physical vapour deposition and, finally, covered with a $\mathrm{SiO}_{x} \mathrm{C}_{y}$ top layer. The resulting uniform coating displayed a thickness of approximately $90 \mathrm{~nm}$, which was measured by spectral ellipsometry (IFAM Fraunhofer Institute, Bremen, Germany) (Khalilpour et al., 2010).

\section{Animal study}

In total, 16 adult female Merino sheep (4-6 years, $90-118 \mathrm{~kg}$ ) were randomly assigned to two surgical groups (each $n=8$ ). One group received silvercoated, the other group uncoated $\mathrm{Ti}_{6} \mathrm{Al}_{4} \mathrm{~V}$ implants. To compare the performance of the implants under different load-bearing conditions, the devices were implanted bilaterally in unloaded drill-hole defects in the trabecular bone at the medial femoral condyle 
and in the cortical bone at the medial tibial diaphysis as well as in a well-established weight-bearing defect at the proximal tibial metaphysis, as previously described (Fig. 1) (Ignatius et al., 1997).

2 months after surgery, peripheral blood samples of 4 animals of the coated-implant group were collected and subjected to analysis of total silver content. After 6 months, the implants and surrounding bone were explanted for macroscopic, biomechanical and histological analyses to assess osseointegration and biocompatibility. Additionally, peripheral blood samples, samples of liver and kidney and local draining lymph nodes as well as samples of soft tissue and bone surrounding the implant were collected for analysis of total silver content.

\section{Surgery}

All surgical interventions were performed under general isoflurane anaesthesia (Isofluran Baxter, Baxter Deutschland $\mathrm{GmbH}$, Unterschleißheim, Germany). Surgery was carried out on both hind limbs. A medial surgical approach was applied to gain access to the knee joint region and a standardised drill-hole defect (diameter: $10 \mathrm{~mm}$; depth: $15 \mathrm{~mm}$ ) was created in the trabecular bone of the medial femoral condyle. At the proximal tibia, approximately $3 \mathrm{~mm}$ below and parallel to the medial tibial plateau, a standardised wedge-shaped defect (length: $24 \mathrm{~mm}$; width: $14 \mathrm{~mm}$; height: $7 \mathrm{~mm}$ ) was created as previously described (Ignatius et al., 1997). Finally, a cylindrical defect (diameter: $5 \mathrm{~mm}$; depth: $8 \mathrm{~mm}$ ) was drilled at the medial side of the tibial diaphysis, $75 \mathrm{~mm}$ below the wedge-shaped defect at the tibial metaphysis. The defects were flushed with sterile saline to remove bone debris before the implants were press-fit inserted. Finally, the wound was closed in layers. Intra- and postoperatively, the sheep received carprofen analgesia $(4 \mathrm{mg} / \mathrm{kg}$ body weight, subcutaneously; Rimadyl ${ }^{\circledR} 50$ mg/ $\mathrm{mL}$, Pfizer Deutschland $\mathrm{GmbH}$, Berlin, Germany) and amoxicillin trihydrate $(10 \mathrm{mg} / \mathrm{kg}$ body weight, subcutaneously; Veyxyl ${ }^{\circledR}$ LA $20 \%$, Veyx-Pharma $\mathrm{GmbH}$, Schwarzenbronn, Germany) for antibiotic prophylaxis over $3 \mathrm{~d}$. After 6 months, all animals were sacrificed.

\section{Sample preparation and macroscopic analysis}

Directly after sacrifice, peripheral blood samples, samples of liver and kidney and local draining lymph nodes (nodus lymphoideus popliteus) were collected for analysis of total silver content. The femur and tibia of both hind limbs of each sheep were explanted for comprehensive post-mortem analyses. Devices implanted in one hind limb were used for biomechanical analysis, whereas implants of the other side were used for histological evaluation, the side for either evaluation being chosen randomly. The implants and surrounding bone were inspected for any macroscopically visible abnormality. Furthermore, samples of soft tissue and bone surrounding the implants were collected for silver analysis.

\section{Analyses of the tissue silver content}

Peripheral blood samples of 4 animals of the coatedimplant group, collected 2 months after surgery, $(n=4)$ and samples of peripheral blood, liver, kidney, local draining lymph nodes as well as soft tissue and bone surrounding the implants of all animals of the coated-implant group, collected at sacrifice, were subjected to silver analysis $(n=8) .4$ animals of the control group served as controls. Blood, liver, kidney, lymph nodes and soft tissue were digested in an UV-digestion apparatus using $65 \%$ nitric acid $\left(\mathrm{HNO}_{3}\right)$ and $40 \%$ hydrogen peroxide $\left(\mathrm{H}_{2} \mathrm{O}_{2}\right)$. Bone

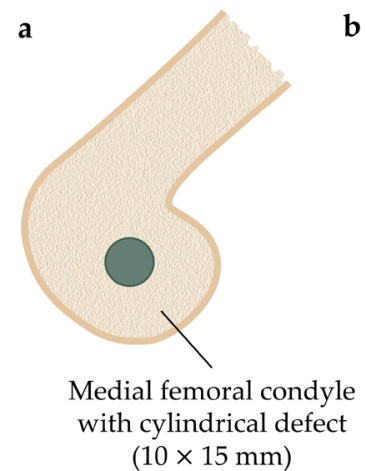

b

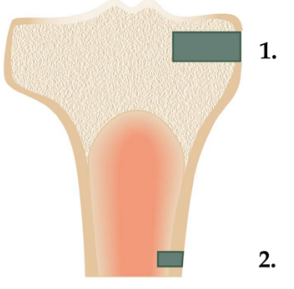

Proximal tibia with wedge-shaped defect (1.) below the medial tibial plateau $(24 \times 14 \times 7 \mathrm{~mm})$ and cylindrical defect (2.) in the cortical bone of the tibia shaft $(5 \times 8 \mathrm{~mm})$

c
Screw threads for biomechanical pull-

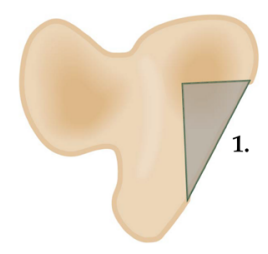

d out tests after implantation

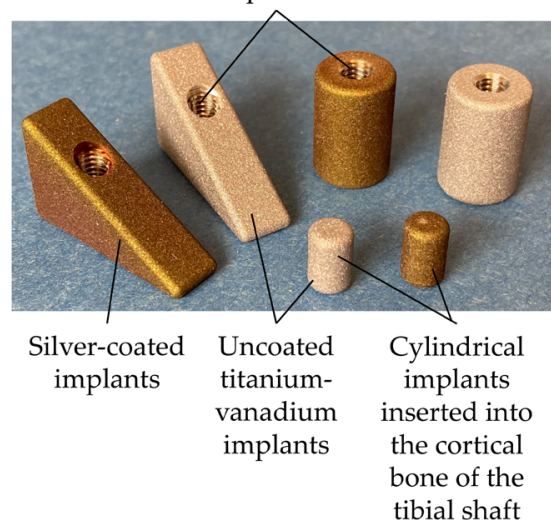

Fig. 1. Schematic illustrations of the femoral and tibial bone defects. (a) Cylindrical defect $(10 \times 15 \mathrm{~mm})$ in the trabecular bone of the medial femoral condyle. Medial view. (b) 1 . Wedge-shaped defect $(24 \times 14 \times 7 \mathrm{~mm})$ in the trabecular bone of the tibial metaphysis, $3 \mathrm{~mm}$ below the tibial plateau. 2 . Cylindrical defect $(5 \times 8 \mathrm{~mm})$ in the cortical bone of the tibial diaphysis. Frontal view. (c) Wedge-shaped defect below the medial tibial plateau. Top view. (d) Photograph of the silver-coated and uncoated titanium-vanadium implants. Implants, which were biomechanically tested within a pull-out test until failure (femoral cylinders and tibial wedgeshaped implants), were equipped with a screw-thread. 
samples were leached with hot nitric acid $\left(\mathrm{HNO}_{3}\right.$ $65 \%, 1: 10)$ to detect silver mainly situated at the bone surface that was in contact with the implant. An aliquot of each sample was measured by inductively coupled plasma mass spectrometry, according to EN ISO 17294-2 guidelines (Web Ref. 2).

\section{Biomechanical evaluation}

To mechanically assess the bony integration of the implants, the cylindrical implants of the femoral condyle and the wedge-shaped implants of the tibial metaphysis (each $n=8$ per group) were subjected to a pull-out test until failure. Bone samples were embedded in polymethyl methacrylate (Technovit ${ }^{\circledR}$ 3040, Kulzer GmbH, Wehrheim, Germany) and mounted in a standard material testing machine (Zwick Z10, Zwick/Roell GmbH \& Co. KG, Ulm, Germany). An adapter was used to connect the implants to a $10 \mathrm{kN}$ load cell (Z12, HBM GmbH, Darmstadt, Germany; accuracy $\leq 0.25 \%$ ) and a tensile load was applied at a constant velocity of $2 \mathrm{~mm} /$ min until failure. The maximum force $F_{\max }$ in $\mathrm{N}$ was determined and the shear strength $\tau$ in $\mathrm{N} / \mathrm{mm}$ of the material-bone interface was calculated as (Eq. 1)

$$
\tau=\frac{F_{\max }}{A}
$$

where $A$ is the contact area between bone and implant in $\mathrm{mm}^{2}$.

To assess bony integration of the cylindrical implants in the tibial diaphysis ( $n=8$ per group), a push-out test until failure was performed. A cylindrical indenter (diameter $=5 \mathrm{~mm}$ ) was connected to a $10 \mathrm{kN}$ load cell (U1, HBM GmbH; accuracy $\leq 0.22 \%$ ) and a compressive load was applied to the cylindrical implant at a constant velocity of $2 \mathrm{~mm} / \mathrm{min}$ until failure. Thereby, force was applied perpendicular to the tibial cortex. From the load-displacement curve, the maximum force $F_{m}$ in $\mathrm{N}$ was determined and the shear strength $\tau$ in $\mathrm{N} /$ $\mathrm{mm}$ was calculated using Eq. 1.

\section{Histological evaluation}

Defect regions with approximately $10 \mathrm{~mm}$ of surrounding bone were processed for non-decalcified bone histology. In brief, bone specimens were fixed in $4 \%$ buffered formaldehyde for up to $5 \mathrm{~d}$, dehydrated in an ascending series of ethanol and embedded in methyl methacrylate (Merck KGaA). Using the sawing and grinding technique of Donath and Breuner, histological slices of $70 \mu \mathrm{m}$ thickness were prepared and the surface was stained with Giemsa according to standard protocols (Donath and Breuner, 1982).

Slices of the femoral and tibial cylinders as well as of the tibial wedge-shaped implants (each $n=8$ per group) were evaluated qualitatively at different magnifications using a light microscope (DMI6000B, Leica). Surrounding bone and the bone-material interface were assessed with regard to the following parameters: vitality of the bone cells, contact area between bone and implant, inflammation, coating (particles in the surrounding soft/hard tissue). The extent of bone apposition was quantified for each implant by light microscopy (Axiophot 451887, Carl Zeiss) at 50-fold magnification using a software for histomorphometric analysis (Osteomeasure ${ }^{\mathrm{TM}}$, Osteometrics Inc., Decatur, GA, USA). The relative surface of the implant to which the mineralised bone was attached, was determined by dividing by the length of the total implant surface available for tissue apposition.

\section{Statistics}

Prior to the animal experiment, the required sample size was calculated by a statistician at the Institute of Epidemiology and Medical Biometry, Ulm University. Statistical analyses were performed using GraphPad $^{\circledR}$ Prism (Graph Pad Software Inc.). The Gaussian distribution of the obtained mechanical and histological data was checked using the ShapiroWilk normality test. Then, normally distributed data were analysed using unpaired $t$-tests to evaluate differences between coated and uncoated titanium implants. When normal distribution was not given, Mann-Whitney-U-test was performed. Potential influences of mechanical loading on implant integration and bone regeneration (implant location at tibial plateau vs. femoral condyle) were assessed using a paired $t$-test or Wilcoxon signed-rank test. Data of the silver analyses were statistically analysed using a non-parametric Mann-Whitney-U-test. The level of significance was defined as $p \leq 0.05$.

\section{Results}

There were no complications during surgery or in the post-operative period. After 3 to 5 post-operative days, sheep returned to a normal gait. In the further course of the study, sheep displayed no abnormalities in movement and there were no macroscopically visible signs of inflammation or disturbed wound healing. When the implants were retrieved after 6 months, there were no visible macroscopic signs of inflammation. All implants were tightly integrated into vital bone with a layer of fibrous or cartilaginous tissue or bone covering the lateral implant surface.

\section{Analyses of the tissue silver content}

2 months after surgery, silver content in peripheral blood samples was below the detection limit of $3 \mu \mathrm{g} /$ $\mathrm{kg}$. After 6 months implantation time, total silver content in blood, kidney and lymph nodes also remained below the detection limit of $3 \mu \mathrm{g} / \mathrm{kg}$ in both groups with coated or uncoated implants (Table 1). In both groups, the highest silver concentration was detected in the liver, with no significant differences between the groups. The silver content of tissue and bone surrounding the implants was significantly higher in the group that received the silver-coated implants. 
Table 1. Results of the silver analyses in the silver-coated and control groups. Total silver content (in $\mu \mathrm{g} / \mathrm{kg}$ ) was determined using inductively coupled plasma mass spectrometry. The silver content of soft tissue and bone in the silver-coated group was significantly higher when compared to the control group. Median (range); ${ }^{a} p \leq 0.05$.

\begin{tabular}{|c|c|c|c|c|c|c|c|}
\hline & $\begin{array}{c}\text { Animals } \\
(n)\end{array}$ & Blood & Liver & Kidney & $\begin{array}{c}\text { Nodus lymphoideus } \\
\text { popliteus - right hind limb }\end{array}$ & $\begin{array}{c}\text { Nodus lymphoideus } \\
\text { popliteus - left hind limb }\end{array}$ & $\begin{array}{c}\text { Soft tissue } \\
\text { and bone }\end{array}$ \\
\hline $\begin{array}{c}\text { Silver- } \\
\text { coated } \\
\text { group }\end{array}$ & 8 & $<3$ & $\begin{array}{c}34 \\
(15-98)\end{array}$ & $<3$ & $<3$ & $<3$ & $9(6-21)^{a}$ \\
\hline $\begin{array}{c}\text { Control } \\
\text { group }\end{array}$ & 4 & $<3$ & $\begin{array}{c}20 \\
(13-62)\end{array}$ & $<3$ & $<3$ & $<3$ & $5(4-6)^{a}$ \\
\hline
\end{tabular}

\section{Shear strength $\tau$}

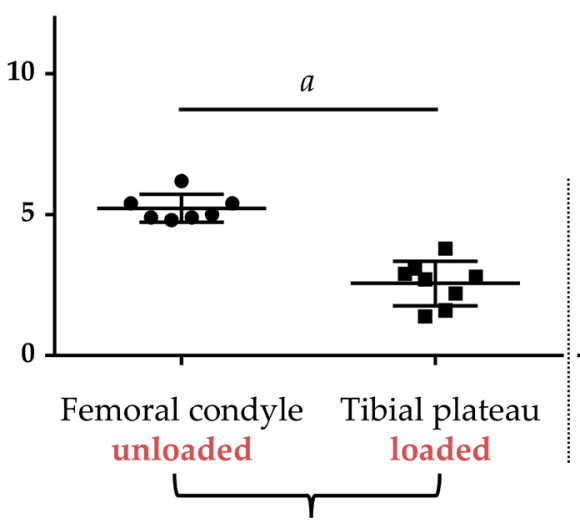

Coated implants

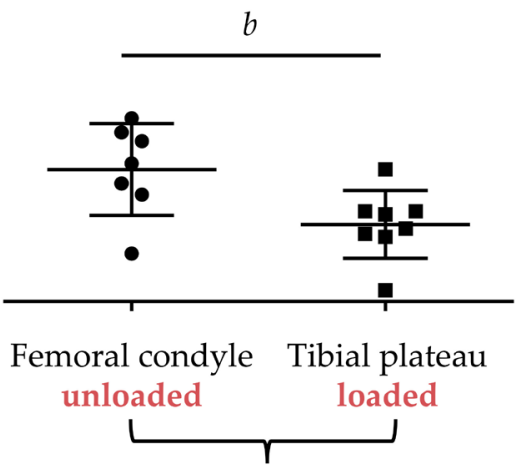

Uncoated implants
Fig. 2. Shear strength of the coated and uncoated devices implanted in the trabecular bone of femur and tibia. The silver coating did not significantly influence interfacial shear strength of the femoral (unloaded condition) and tibial (loaded condition) titanium implants when compared to uncoated implants. Coated and uncoated titanium implants inserted into the weight-bearing defect displayed a reduced shear strength when compared to unloaded implants. Mean \pm standard deviation; ${ }^{\mathrm{a}, \mathrm{b}} p \leq 0.05$.

\section{Devices implanted in trabecular bone}

Mechanical evaluation of osseointegration

In each group, one femoral sample had to be excluded from the evaluation because the implant could not be pulled out of the femoral condyle. The implants were so well integrated that the pull-out force exceeded the measuring capacity of the used $10 \mathrm{kN}$ load cell. The silver coating did not significantly influence the interface shear strength of the titanium implants, whether implanted in femur or tibia $(p=0.4$ and $p=0.7$, respectively) (Fig. 2). However, mechanical implant integration was significantly influenced by mechanical loading. Both coated and uncoated titanium implants inserted into the weight-bearing defect displayed an up to $50 \%$ reduced shear strength when compared to unloaded implants.

\section{Histological evaluation}

All implants, which were inserted in the trabecular bone of femur and tibia, were surrounded by a newly formed bony lamella with abundant osteoid formation (Fig. 3a,b). There were no inflammatory cells or abraded particles of the coating detectable in the surrounding of the implants. The silver coating did not significantly influence bone apposition at any implant location. Bone apposition was the most for the devices implanted under non-loaded conditions at the femoral condyle (Fig. 3c).

\section{Devices implanted in cortical bone}

Mechanical evaluation of the osseointegration

The shear strength of the cylindrical devices implanted in the tibial diaphysis was not significantly different between coated or uncoated implants $(p=0.4)$ (Fig. 4a).

\section{Histological evaluation}

The cortical bone surrounding the implants was vital and a bone lamella had formed around the devices (Fig. 5). No signs of inflammation or particles derived from the implant surface were detectable. Bone apposition to the implants was not significantly influenced by the silver coating (Fig. 4b).

\section{Discussion}

The aim of the present study was to evaluate the osseointegration of titanium-vanadium implants coated with a novel antibacterial silver coating in a mechanically loaded bone defect model in sheep. The study demonstrated that osseointegration of titanium 
a

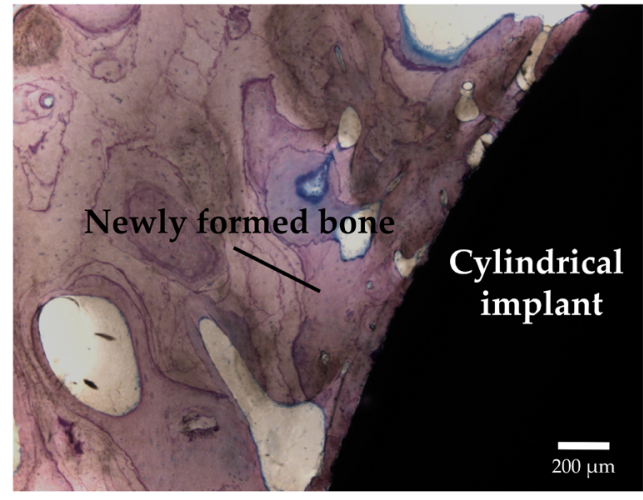

Low magnification

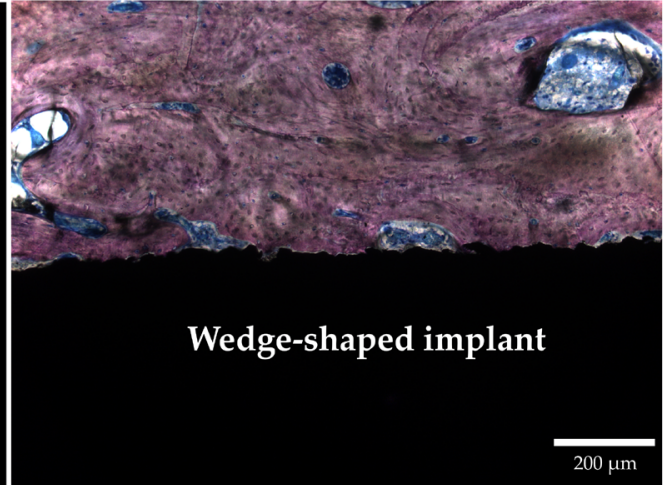

High magnification

b

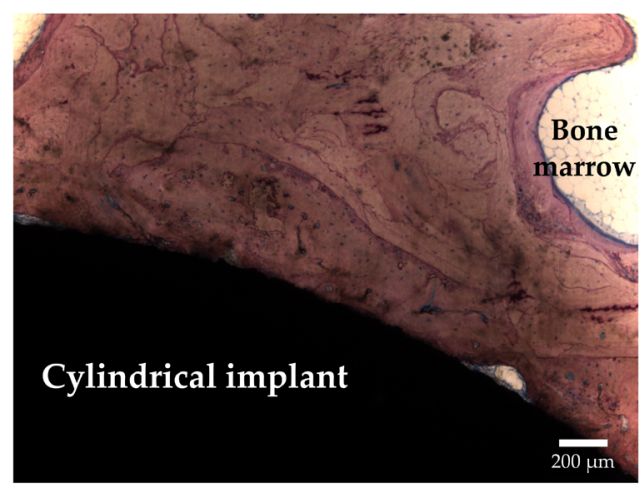

Low magnification

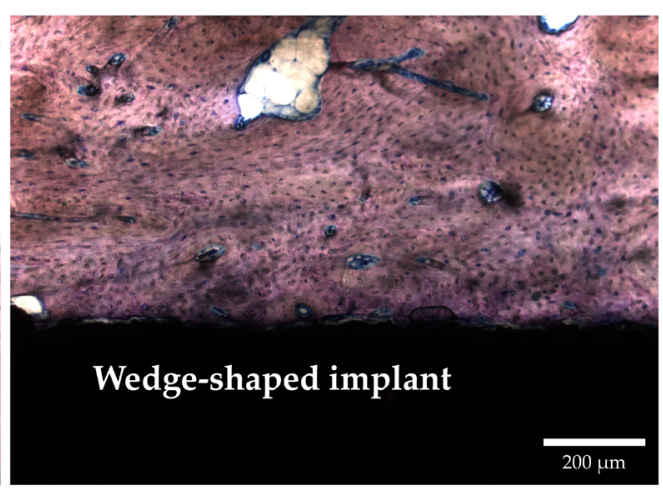

High magnification

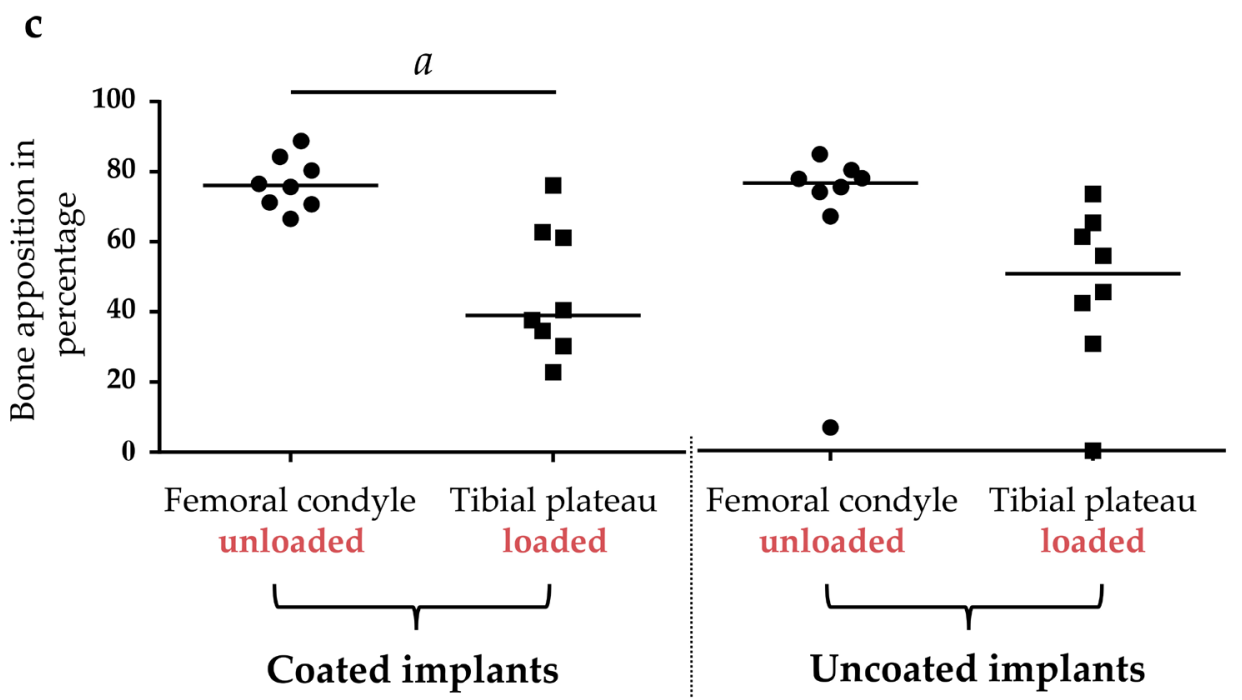

Fig. 3. Histological evaluation of devices inserted into trabecular bone. All implants were surrounded by a newly formed bony lamella with abundant osteoid formation. (a) Example of histological images of femoral and tibial HyProtect ${ }^{\mathrm{TM}}$-coated implants. (b) Example of histological images of femoral and tibial uncoated implants. Giemsa staining. Cells and nuclei are stained in different shades of blue, collagen and osteoid in pale blue, cartilage matrix in red to violet and mineralised bone matrix in pink to pale pink. (c) Bone apposition in percentage of implant surface for coated and uncoated implants in the trabecular bone. Bone apposition was the most for the devices implanted under non-loaded conditions at the femoral condyle. The silver coating did not significantly influence bone apposition at any implant location as there was no difference between coated and uncoated implants. Median and individual values; ${ }^{a} p \leq 0.05$. 
implants was not negatively affected by the coating, even under load-bearing conditions. The coating exhibited excellent biocompatibility and both the local and systemic silver concentrations remained below toxic levels, suggesting that the new silver coating might be suitable for load-bearing implants, including endoprostheses.

The general antibacterial efficacy of silver-coated orthopaedic devices was previously demonstrated (Hardes et al., 2010; Wilding et al., 2016). The bactericidal effect of silver is based on its binding to membranes, enzymes and nucleic acids, thereby impairing crucial cell functions (Brutel de la Riviere et al., 2000; Hollinger, 1996). However, eukaryotic cells are also affected in a dose-dependent manner (Chambers et al., 1962; Tweden et al., 1997). Accordingly, it was demonstrated that silver concentrations > 1200 ppm $(1.2 \mathrm{~g} / \mathrm{L})$ had strong cytotoxic effects on fibroblasts in vitro (Tweden et al., 1997). The specific influence of silver particles and elementary silver on bone cells has been also investigated in vitro (Albers et al., 2013; Hardes et al., 2007b). Elementary silver, displaying no cytotoxicity at concentrations of $5-10 \mathrm{mg} /$ well (six well plate), actually stimulates osteogenic differentiation of osteoblastic cells (Hardes et al., $2007 b$ ). In contrast, another study revealed that silver nanoparticles exhibit strong cytotoxic effects in primary osteoblasts and osteoclasts, already at a bactericidal concentration of $128 \mu \mathrm{g} / \mathrm{mL}$. Thereby, osteoblasts are more susceptible when compared to osteoclasts (Albers et al., 2013). Preclinical and clinical studies on silver-coated orthopaedic implants have generally shown good biocompatibility and health risks associated with systemic absorption of silver ions are considered to be low (Gosheger et al., 2004; Hardes et al., 2007a; Hardes et al., 2010; Hussmann et al., 2013; Wilding et al., 2016). Nevertheless, the release a

Shear strength $\boldsymbol{\tau}$

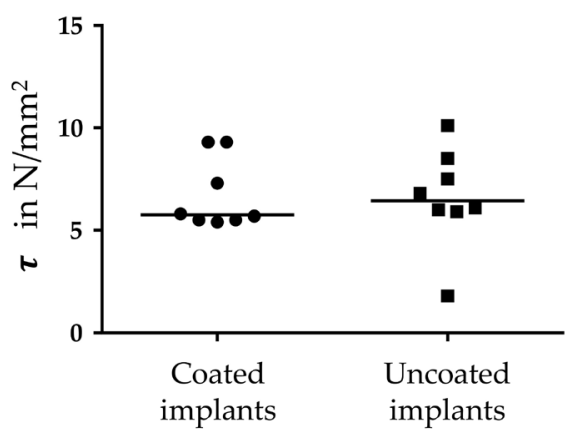

b

Bone apposition in percentage

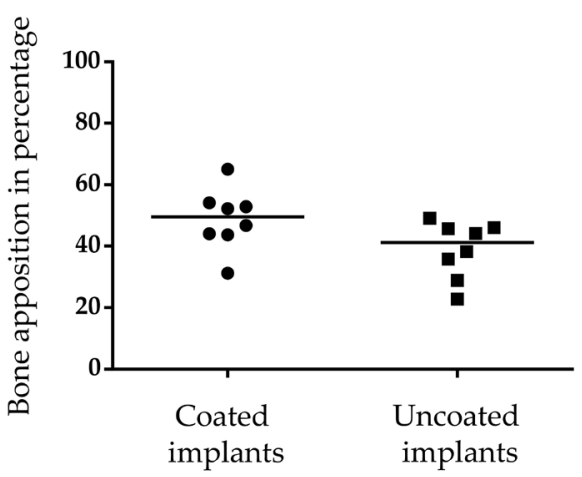

Fig. 4. Osseointegration of devices inserted into the cortical bone. (a) Shear strength in $\mathrm{N} / \mathrm{mm}^{2}$ of cylindrical implants inserted into the tibial diaphysis. There was no difference between coated and uncoated implants. (b) Bone apposition in percentage of implant surface of the coated and uncoated devices implanted in the tibial diaphysis. Bone apposition to the implants was not influenced by the silver coating as there was no difference between coated and uncoated devices. Median and individual values.

a

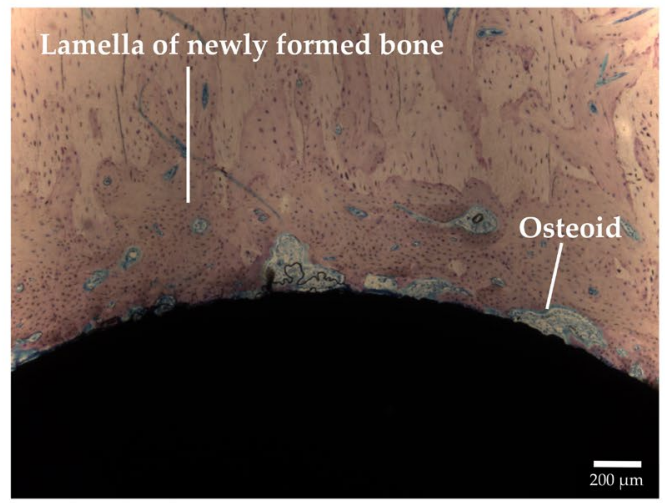

b

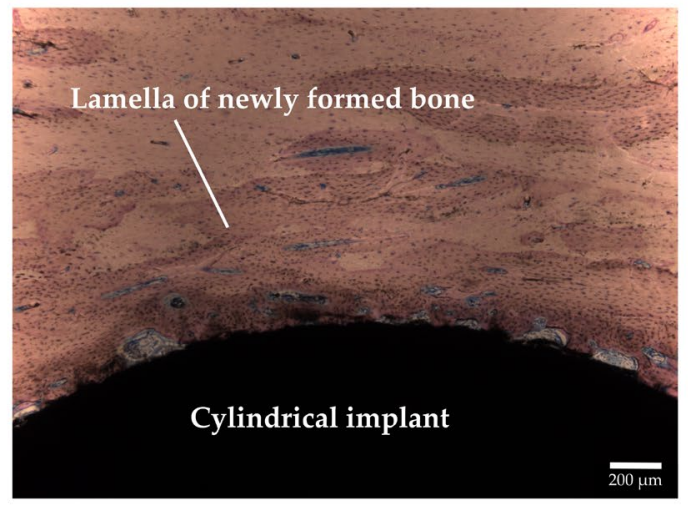

Fig. 5. Histological evaluation of devices inserted into cortical bone. (a) Histological image of a HyProtect ${ }^{\mathrm{TM}}$-coated implant in the tibial diaphysis. (b) Histological image of an uncoated implant in the tibial diaphysis. In both animals, cortical bone surrounding the implants was vital and a lamella of new bone has formed around the implant. Giemsa staining. Cells and nuclei are stained in different shades of blue, collagen and osteoid in pale blue, cartilage matrix in red to violet and mineralised bone matrix in pink to pale pink. 
of silver from antibacterial implant coatings should be reduced to the therapeutically necessary minimum to avoid potential cytotoxic side-effects and to allow for good osseointegration, particularly in the case of load-bearing devices.

The coating investigated in the present study consists of a $\mathrm{SiO}_{\mathrm{x}} \mathrm{C}_{\mathrm{y}}$ plasma polymer layer with embedded silver particles (HyProtect ${ }^{\mathrm{TM}}$ ) (Khalilpour et al., 2010). Thereby, silver is not in direct contact with the surrounding tissue and a controlled release of silver ions is ensured. Exhibiting a quite low silver content of $2.7 \mu \mathrm{g} / \mathrm{cm}^{2}$, in vitro antibacterial efficacy against Staphylococcus epidermidis, methicillinsensitive $S$. aureus, methicillin-resistant $S$. aureus as well as in vivo efficacy against methicillin-sensitive S. epidermidis and in vivo biocompatibility are demonstrated (Fabritius et al., 2020; Khalilpour et al., 2010). Recently, a clinical case report of the successful treatment of a recurrent periprosthetic joint infection using a HyProtect ${ }^{\mathrm{TM}}$-coated intramedullary arthrodesis system has been published (Alt et al., 2019). The applied arthrodesis nail exhibits a reduced silver content when compared to a silver-coating technology, which is already in routine clinical use for modular tumour and revision implants (MUTARS ${ }^{\circledR}$, Implantcast, Buxtehude, Germany) (Hardes et al., 2007a). Alt et al. (2019) have assessed silver content in wound drainage fluid 24 and 48 h after surgery to estimate local silver concentrations. Exhibiting silver contents of $170 \mathrm{ppb}$ and $57 \mathrm{ppb}$ at 24 and $48 \mathrm{~h}$, respectively, values remained far beyond toxic levels. 26 months after implantation of the silvercoated arthrodesis nail, silver serum levels remained $<2 \mathrm{ppb}(2 \mu \mathrm{g} / \mathrm{kg})$ (Alt et al., 2019). Accordingly, in the present study, elemental analysis revealed silver concentrations in peripheral blood below the detection limit of the used analysis method $(3 \mu \mathrm{g} / \mathrm{kg})$. The slightly elevated silver concentrations observed in liver tissue of the coated implant group have to be considered in view of the fact that the liver is the primary organ for silver accumulation and excretion (Lansdown, 2010). Even in patients with blood silver concentrations $>200 \mu \mathrm{g} / \mathrm{L}$ or advanced argyria, there is no evidence for irreversible pathological hepatic damage due to silver (Lansdown, 2010). According to the scientific committee on medicinal products and medical devices of the European Commission, the amount of silver which can be safely consumed daily by humans is $5 \mu \mathrm{g} / \mathrm{kg}$ body weight. Thereby, daily consumption of drinking water (silver concentration $\sim 100 \mu \mathrm{g} / \mathrm{L}$ ), milk (silver concentration 27-54 $\mu \mathrm{g} / \mathrm{L}$ ) and certain foods (e.g. mushrooms) contributes substantially to the daily silver uptake (Commission, 2010).

Osseointegration is described as the process of healing and anchorage of an implant into the surrounding bone. Thereby, direct contact between bone and implant without fibrous encapsulation is formed and maintained under functional loads (Branemark et al., 2001). The bony integration of a medical device is influenced by various factors, including material and surface characteristics of the implant as well as the biological and mechanical environment at the interface (Soballe et al., 1992). Excessive micromotions at the interface compromise not only the osseointegration but could also influence surface characteristics of the implants. Consequently, new materials and coatings for orthopaedic implants, which have to tightly integrate into bone, i.e. endoprostheses, should be analysed under dynamic loading conditions to assess their stability and functionality. Therefore, in the present study, non-loaded drill hole defects in cortical and trabecular bone and a well-established load-bearing defect model in the proximal sheep tibia, which was previously mechanically characterised (Ignatius et al., 1997; Kanter et al., 2014; Reitmaier et al., 2018; Simon et al., 2003), were used. Under non-loaded conditions, both coated and uncoated titanium implants were very well integrated into both cortical and trabecular bone. No signs of inflammation were found, thereby confirming previous reports about the excellent biocompatibility of titanium (Ignatius et al., 1997). Furthermore, biocompatibility of the silver coating, which has already been demonstrated in an earlier study after subcutaneous implantation in rabbits (Khalilpour et al., 2010), was also confirmed after implantation into bone. However, it should be noted that the histological grinding sections evaluated did not allow for precise cellular histology. Even under mechanically loaded conditions, the silver coating did not negatively influence bone regeneration or implant integration, as the direct bone contact to the implant surface and the shear strength in the interface were not significantly different between coated or uncoated titanium implants. However, compared to the implants within the non-loaded drill-hole defects, implants inserted into the load-bearing defect displayed a decreased bone apposition and a reduced maximum pull-out force, independently of the coating, indicating that mechanical load decreased osseointegration. Using a finite element model, it was previously shown that in the load-bearing model, implants are mainly subjected to axial compression; thereby, approximately $33 \%$ of the total axial kneejoint force is transferred (Simon et al., 2003). The resulting micromotions at the interface depend on implant stiffness and are calculated to be in the range of $6 \mu \mathrm{m}$ for titanium implants (Simon et al., 2003). The good bony integration of titanium implants using this loaded implantation model has already been demonstrated and confirmed by Ignatius et al. (1997). The critical interface motions preventing stable osseointegration are regarded to be in the range of $100 \mu \mathrm{m}$, but strongly depend on the physical and chemical surface characteristics of an implant and on the biological environment (Pilliar et al., 1986; Soballe et al., 1992). The load-bearing model applied in the present study allows for the osseointegration of titanium, but not of inert aluminium oxide ceramics, being only osseointegrated under nonloaded conditions (Ignatius et al., 2005). This suggests 
that this model is sufficiently critical to assess the functionality of weight-bearing implants and coatings because the resulting micromovements can prevent stable osseointegration of certain materials.

\section{Conclusions}

The present results revealed that the novel silver coating did not negatively influence bone regeneration or implant integration in trabecular or cortical bone even under mechanically loaded conditions. Considering the increasing clinical problem of multiresistant pathogens, the new coating might be useful to prevent implant-associated infections also in load-bearing applications, including endoprostheses. Further pre-clinical studies should address this question, for example, by using animal models of bone infection.

\section{Acknowledgements}

We would like to thank Uschi Maile and Cherisé Grieser for preparing the histological samples and for their technical support during surgery as well as Sebastian Höppler for his support during surgery and post-mortem analyses. This work was financially supported by the Bayerisches Staatsministerium für Wirtschaft und Medien, Energie und Technologie, Projektträger Bayern, Förderinitiative Medizintechnik Bayern [MED-1604-001/-002]. The authors declare no conflict of interest.

\section{References}

Ahrens H, Gosheger G, Streitbürger A, Gebert C, Hardes J (2006) Antimikrobielle Silberbeschichtung von Tumorprothesen. Der Onkologe 12: 145-151.

Albers CE, Hofstetter W, Siebenrock KA, Landmann R, Klenke FM (2013) In vitro cytotoxicity of silver nanoparticles on osteoblasts and osteoclasts at antibacterial concentrations. Nanotoxicology 7: 30-36.

Alt V, Bechert T, Steinrucke P, Wagener M, Seidel P, Dingeldein E, Domann E, Schnettler R (2004) An in vitro assessment of the antibacterial properties and cytotoxicity of nanoparticulate silver bone cement. Biomaterials 25: 4383-4391.

Alt V, Heiss C, Rupp M (2019) Treatment of a recurrent periprosthetic joint infection with an intramedullary knee arthrodesis system with lowamount metallic silver coating. J Bone Jt Infect 4: 111-114.

Anderson DJ, Sexton DJ, Kanafani ZA, Auten G, Kaye KS (2007) Severe surgical site infection in community hospitals: epidemiology, key procedures, and the changing prevalence of methicillin-resistant Staphylococcus aureus. Infect Control Hosp Epidemiol 28: 1047-1053.
Atiyeh BS, Costagliola M, Hayek SN, Dibo SA (2007) Effect of silver on burn wound infection control and healing: review of the literature. Burns 33: 139148.

Bhandari M, Guyatt G, Tornetta P 3rd, Schemitsch EH, Swiontkowski M, Sanders D, Walter SD (2008) Randomized trial of reamed and unreamed intramedullary nailing of tibial shaft fractures. J Bone Joint Surg Am 90: 2567-2578.

Branemark R, Branemark PI, Rydevik B, Myers RR (2001) Osseointegration in skeletal reconstruction and rehabilitation: a review. J Rehabil Res Dev 38: 175-181.

Brutel de la Riviere A, Dossche KM, Birnbaum DE, Hacker R (2000) First clinical experience with a mechanical valve with silver coating. J Heart Valve Dis 9: 123-130.

Busscher HJ, van der Mei HC, Subbiahdoss G, Jutte PC, van den Dungen JJ, Zaat SA, Schultz MJ, Grainger DW (2012) Biomaterial-associated infection: locating the finish line in the race for the surface. Sci Transl Med 4: 153rv110. DOI: 10.1126/scitranslmed.3004528.

Chambers CW, Proctor CM, Kabler PW (1962) Bactericidal effect of low concentrations of silver. J Am Water Works Assoc 54: 208-216.

Commission European (2010) Toxicological data on colouring agents for medicinal products: E 174 silver.

Darouiche RO (2004) Treatment of infections associated with surgical implants. N Engl J Med 350: 1422-1429.

Donath K, Breuner G (1982) A method for the study of undecalcified bones and teeth with attached soft tissues. The Sage-Schliff (sawing and grinding) technique. J Oral Pathol 11: 318-326.

Elechiguerra JL, Burt JL, Morones JR, CamachoBragado A, Gao X, Lara HH, Yacaman MJ (2005) Interaction of silver nanoparticles with HIV-1. J Nanobiotechnol 3: 6. DOI: 10.1186/1477-3155-3-6.

Fabritius M, Al-Munajjed AA, Freytag C, Julke H, Zehe M, Lemarchand T, Arts JJ, Schumann D, Alt V, Sternberg K (2020) Antimicrobial silver multilayer coating for prevention of bacterial colonization of orthopedic implants. Materials (Basel) 13: 1415. DOI: 10.3390/ma13061415.

Gosheger G, Hardes J, Ahrens H, Streitburger A, Buerger H, Erren M, Gunsel A, Kemper FH, Winkelmann W, Von Eiff C (2004) Silver-coated megaendoprostheses in a rabbit model-an analysis of the infection rate and toxicological side effects. Biomaterials 25: 5547-5556.

Hardes J, Ahrens H, Gebert C, Streitbuerger A, Buerger H, Erren M, Gunsel A, Wedemeyer C, Saxler G, Winkelmann W, Gosheger G (2007a) Lack of toxicological side-effects in silver-coated megaprostheses in humans. Biomaterials 28: 28692875.

Hardes J, Streitburger A, Ahrens H, Nusselt T, Gebert C, Winkelmann W, Battmann A, Gosheger G (2007b) The influence of elementary silver versus titanium on osteoblasts behaviour in vitro using 
human osteosarcoma cell lines. Sarcoma 2007: 26539. DOI: $10.1155 / 2007 / 26539$.

Hardes J, von Eiff C, Streitbuerger A, Balke M, Budny T, Henrichs MP, Hauschild G, Ahrens H (2010) Reduction of periprosthetic infection with silver-coated megaprostheses in patients with bone sarcoma. J Surg Oncol 101: 389-395.

Hollinger MA (1996) Toxicological aspects of topical silver pharmaceuticals. Crit Rev Toxicol 26: 255-260.

Hussmann B, Johann I, Kauther MD, Landgraeber S, Jager M, Lendemans S (2013) Measurement of the silver ion concentration in wound fluids after implantation of silver-coated megaprostheses: correlation with the clinical outcome. BioMed Res Int 2013: 763096. DOI: 10.1155/2013/763096.

Ignatius A, Peraus M, Schorlemmer S, Augat P, Burger W, Leyen S, Claes L (2005) Osseointegration of alumina with a bioactive coating under load-bearing and unloaded conditions. Biomaterials 26: 2325-2332.

Ignatius A, Unterricker K, Wenger K, Richter M, Claes L, Lohse P, Hirst H (1997) A new composite made of polyurethane and glass ceramic in a loaded implant model: a biomechanical and histological analysis. J Mater Sci Mater Med 8: 753-756.

Kanter B, Geffers M, Ignatius A, Gbureck U (2014) Control of in vivo mineral bone cement degradation. Acta Biomater 10: 3279-3287.

Khalilpour P, Lampe K, Wagener M, Stigler B, Heiss C, Ullrich MS, Domann E, Schnettler R, Alt $\mathrm{V}$ (2010) Ag/SiOxCy plasma polymer coating for antimicrobial protection of fracture fixation devices. J Biomed Mater Res B Appl Biomater 94: 196-202.

Kurtz SM, Lau E, Schmier J, Ong KL, Zhao K, Parvizi J (2008) Infection burden for hip and knee arthroplasty in the United States. J Arthroplasty 23: 984-991.

Lansdown AB (2010) A pharmacological and toxicological profile of silver as an antimicrobial agent in medical devices. Adv Pharmacol Sci 2010: 910686. DOI: 10.1155/2010/910686.

McGraw JM, Lim EV (1988) Treatment of open tibial-shaft fractures. External fixation and secondary intramedullary nailing. J Bone Jt Surg Am 70: 900-911.

Parvizi J, Pawasarat IM, Azzam KA, Joshi A, Hansen EN, Bozic KJ (2010) Periprosthetic joint infection: the economic impact of methicillin-resistant infections. J Arthroplasty 25: 103-107.

Percival SL, Bowler PG, Russell D (2005) Bacterial resistance to silver in wound care. J Hosp Infect 60: 1-7.

Pilliar RM, Lee JM, Maniatopoulos C (1986) Observations on the effect of movement on bone ingrowth into porous-surfaced implants. Clin Orthop Relat Res: 108-113.

Reitmaier S, Kovtun A, Schuelke J, Kanter B, Lemm M, Hoess A, Heinemann S, Nies B, Ignatius A (2018) Strontium(II) and mechanical loading additively augment bone formation in calcium phosphate scaffolds. J Orthop Res 36: 106-117.
Rochford ET, Richards RG, Moriarty TF (2012) Influence of material on the development of deviceassociated infections. Clin Microbiol Infect 18: 11621167.

Simon U, Augat P, Ignatius A, Claes L (2003) Influence of the stiffness of bone defect implants on the mechanical conditions at the interface-a finite element analysis with contact. J Biomech 36: 10791086.

Soballe K, Hansen ES, Rasmussen HB, Jorgensen PH, Bunger C (1992) Tissue ingrowth into titanium and hydroxyapatite-coated implants during stable and unstable mechanical conditions. J Orthop Res 10: 285-299.

ter Boo GJ, Grijpma DW, Moriarty TF, Richards RG, Eglin D (2015) Antimicrobial delivery systems for local infection prophylaxis in orthopedic- and trauma surgery. Biomaterials 52: 113-125.

Thakore RV, Greenberg SE, Shi H, Foxx AM, Francois EL, Prablek MA, Nwosu SK, Archer KR, Ehrenfeld JM, Obremskey WT, Sethi MK (2015) Surgical site infection in orthopedic trauma: a casecontrol study evaluating risk factors and cost. J Clin Orthop Trauma 6: 220-226.

Trampuz A, Widmer AF (2006) Infections associated with orthopedic implants. Curr Opin Infect Dis 19: 349-356.

Tweden KS, Cameron JD, Razzouk AJ, Holmberg WR, Kelly SJ (1997) Biocompatibility of silvermodified polyester for antimicrobial protection of prosthetic valves. J Heart Valve Dis 6: 553-561.

Widmer AF (2001) New developments in diagnosis and treatment of infection in orthopedic implants. Clin Infect Dis 33 Suppl 2: S94-106.

Wilding CP, Cooper GA, Freeman AK, Parry MC, Jeys L (2016) Can a silver-coated arthrodesis implant provide a viable alternative to above knee amputation in the unsalvageable, infected total knee arthroplasty? J Arthroplasty 31: 2542-2547.

\section{Web Reference}

1. https://www.iso.org/standard/61089.html [20.06.2020]

2. https://www.iso.org/standard/62962.html [29.06.2020]

\section{Discussion with Reviewer}

Reviewer: The biocompatibility is very important and the study showed that osteointegration was not affected by the silver coating/release. Have the authors also planned to use this coating in an infection model to prove the effectivity of the released silver?

Authors: The evaluation of the osseointegration of the new silver coating in a functional largeanimal model was the primary aim of the study. 
Additional knowledge about the efficacy of the new coating technology for routine clinical application was recently acquired. A study was published, investigating the antibacterial potential of the new silver coating in an infection model in rabbits (Fabritius et al., 2020). Silver-coated K-wires were seeded and pre-incubated with methicillin-sensitive Staphylococcus epidermidis. The K-wires were inserted into the tibial medullary canal of the animals. Noncoated K-wires served as control in another group of animals. After a $7 \mathrm{~d}$ implantation period, rabbits were sacrificed and microbiology revealed a statistically significant pathogen reduction on the surface of silver-coated devices when compared to non-coated devices. 7 of 12 silver-coated K-wires were completely free of pathogens as compared to only 1 pathogenfree K-wire in the control group. The results of the study are supported by the already established use of HyProtect ${ }^{\mathrm{TM}}$-coated fracture fixation devices in the veterinary field. Furthermore, the recently reported successful application in a human patient following revision of a periprosthetic joint infection confirmed the bactericidal potential of the coating and transferability to the human setting (Alt et al., 2019).

Currently, we do not plan an additional preclinical study in a large-animal infection model. Instead, more clinical studies involving a larger number of patients are necessary to confirm the suitability and efficacy of the new coating technology for its routine clinical application.

Editor's note: The Scientific Editor responsible for this paper was Joost de Bruijn. 